\title{
APLIKASI COMPLAINT MANAGEMENT SYSTEM BERBASIS ANDROID DI FAKULTAS SAINS DAN TEKNOLOGI UIN SUSKA RIAU
}

\author{
${ }^{1}$ Idria Maita, ${ }^{2}$ Alfajri \\ ${ }^{1,2}$ Program Studi Sistem Informasi, Fakultas Sains dan Teknologi UIN Suska Riau, \\ J1. HR Soebrantas, KM. 18.5, No. 155, Simpang Baru, Pekanbaru, Indonesia, 28293. \\ Email: ${ }^{1}$ idria79@gmail.com, ${ }^{2}$ alfajri405@gmail.com.
}

\begin{abstract}
ABSTRAK
Universitas Islam Negeri Sultan Syarif Kasim Riau memiliki 6 fakultas, salah satunya yaitu Fakultas Sains dan Teknologi. Banyaknya keluhan yang tidak tersampaikan oleh mahasiswa kepada pihak fakultas disebabkan oleh tidak adanya penghubung yang efektif antara mahasiswa dan pihak fakultas. Hal ini menyebabkan keluhan dari mahasiswa tidak terdengar oleh pihak fakultas. Pada proses sebelumnya masih berlangsung secara manual dan memiliki kekurangan. Complaint Management System adalah sebuah sistem yang dapat membantu dan mempermudah dalam menyampaikan komplain dan memberikan tanggapannya. Mahasiswa dapat menyampaikan komplain dan pihak fakultas bisa memberikan tanggapannya. Agar sistem mudah digunakan maka dibangun berbasis Android, perancangan sistem menggunakan metode Object Oriented Analysis and Design (OOAD), dan pemrograman yang digunakan adalah pemrograman PHP, MySQL dan Java, sedangkan metode pengembangan sistem menggunakan Waterfall dan UML sebagai standar pemodelannya.
\end{abstract}

Kata Kunci: Android, Complaint Management System, OOAD, UML, UAT.

\section{A. PENDAHULUAN}

Complaint adalah ungkapan/pernyataan dan ketidapuasan yang diilustrasikan dalam keluhan menganai kebutuhan dan harapan yang tidak terpenuhi dengan tujuan untuk menuntut pelayanan yang lebih baik [1].

Agar tugas pada Fakultas Sains dan Teknologi UIN Syarif Kasim Riau (UIN Suska Riau) lebih terorganisir, maka dibentuklah 3 buah bidang yaitu Bidang Akademik dan Pembangunan Instuisi, Bidang Administrasi Umum dan Keuangan, dan Bidang kemahasiswaan dan kerja Sama. Bidangbidang ini memiliki tugas yang berbeda-beda, namun pada penelitian ini membatasi ruang lingkup pada Bidang Administrasi Umum dan Keuangan. Bidang Administrasi Umum dan Keuangan memiliki tugas pokok yaitu membawahi pegawaipegawai yang bersifat umum, mengelola keuangan, dan mengelola sarana dan prasarana pada Fakultas Sains dan Teknologi. Pelayanan yang sudah diberikan oleh Bidang Administrasi Umum dan Keuangan dapat diterima dan dirasakan oleh mahasiswa sehingga mahasiswa dapat menilai apakah pelayanan yang sudah diterima sudah sesuai dengan mereka inginkan atau tidak. Saat ini mahasiswa tidak mengerti tata cara menyampaikan keluhan dari mahasiswa kepada Bagian Administrasi Umum dan Keuangan, mekanisme pengaduan yang belum sepenuhnya terpublikasi dan kurangnya sosialisasi sehingga mahasiswa tidak berani menyampaikan keluhan. Prosedur yang saat ini diterapkan memerlukan waktu yang panjang hingga keluhan tersebut ditanggapi.
Banyaknya keluhan mahasiswa terhadap kondisi sarana dan prasarana yang terkesan diabaikan karena belum tersedianya penguhubung yang efektif bagi mahasiswa dan Bagian Administrasi Umum dan Keuangan dalam menangani permasalahan tersebut. Jika keluhan disampaikan menggunakan prosedur saat ini, maka akan menyita banyak waktu dan tenaga mahasiswa, pegawai Administrasi Umum maupun Dekan dalam mengelola data pengaduan dari mahasiswa. Resiko kehilangan data dalam pengarsipan laporan pengaduan mahasiswa rawan terjadi karena penyimpanan data pengaduan tersimpan dalam bentuk hardcopy pada lemari berkas.

Dari permasalahan yang terjadi, perlu solusi seperti aplikasi sebagai sarana dalam penyampaian komplain dimana dengan adanya aplikasi ini maka akan dapat menghubungkan mahasiswa dengan Bagian Administrasi Umum dan Keuangan. Adapun fasilitas yang dimaksud tersebut yaitu Complaint Management System. Complaint Management System ini akan memberikan kemudahan kepada mahasiswa untuk menyampaikan perbaikan bahkan permohonan pengadaan suatu sarana dan prasarana. Agar dalam penggunaan aplikasi lebih efektif dan efisien, maka aplikasi Complaint Management System ini dibangun berbasis Android untuk user level mahasiswa. Hal ini bertujuan agar mahasiswa lebih mudah dalam mengakses aplikasi langsung menggunakan smartphone yang mereka punya. 


\section{B. LANDASAN TEORI}

\section{B.1. Complaint Management System}

Complaint Management System yaitu sistem yang dirancang untuk membantu organisasi dalam pengelolaan proses penanganan keluhan. Melalui ini, akan mudah dalam memanajemen komplain karena menggunakan antarmuka yang menyediakan pengguna baik akhir dan manajemen dengan pandangan yang jelas status saat ini dari semua keluhan, sehingga membantu untuk menyediakan pelanggan dengan tanggapan cepat dan solusi untuk masalah mereka [1].

\section{B.2. Konsep Android}

Android merupakan sistem operasi untuk telepon seluler yang berbasis Linux. Android menyediakan platform terbuka bagi para pengembang untuk menciptakan aplikasi mereka sendiri untuk digunakan oleh bermacam piranti bergerak. Awalnya, Google Inc. membeli Android Inc., pendatang baru yang membuat piranti lunak untuk ponsel. Kemudian untuk mengembangkan Android dibentuklah Open Handset Alliance, konsorsium dari 34 perusahaan peranti keras, peranti lunak, dan telekomunikasi termasuk Google, HTC, Intel, Motorola, Qualcomm, T-Mobile, dan Nvidia [2].

\section{B.3. Object Oriented Analysis and Design (OOAD) dan Unified Modelling Languange \\ Object Oriented merupakan paradigma baru} dalam rekayasa perangkat lunak yang memandang sistem sebagai kumpulan obyek-obyek diskrit yang saling berinteraksi. Yang dimakusd berorientasi obyek adalah bahwa mengorganisasikan perangkat lunak sebagai kumpulan obyek-obyek diskrit yang bekerja sama antara informasi atau struktur data dan perilaku (behavior) yang mengaturnya [3].

Unified Modelling Languange (UML) adalah bahasa permodelan untuk sistem atau perangkat lunak yang berparadigma "berorientasi objek". Permodelan (modelling) sesungguhnya digunakan untuk penyederhanaan permasalahan-permasalahan yang kompleks sedemikian rupa sehingga lebih mudah dipelajari dan dipahami [4].

UML menyediakan beberapa diagram yang menunjukkan berbagai aspek dalam sistem. Namun pada penelitian ini hanya menggunakan 4 buah diagram dari 8 buah diagram yang disediakan UML, yaitu: [3] (1) Usecase Diagram; (2) Sequence Diagram; (3) Activity Diagram; (4) Class Diagram.

\section{B.4. Konsep Metode Waterfall}

Waterfall disebut model sekuensial linear atau alur hidup perangkat lunak secara skuensial atau terurut dimulai dari perencanaan, analisis, perencanaan, implementasi, pengujian dan pemeliharaan [4]. Untuk ilustrasi model Waterfall dapat dilihat pada Gambar 1.

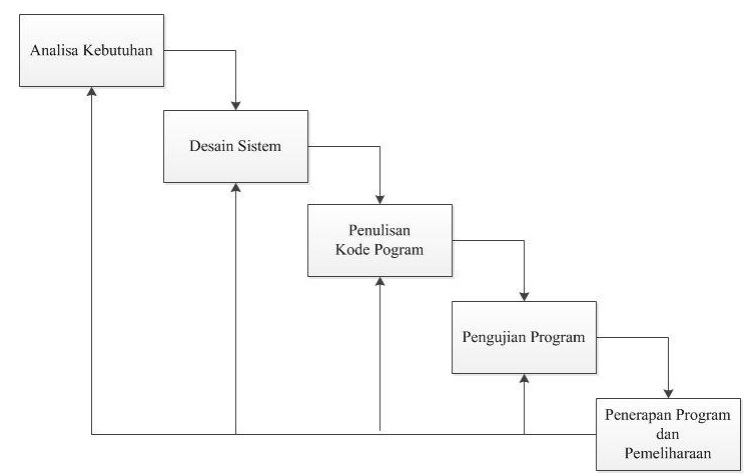

Gambar 1. Ilustrasi Model Waterfall

\section{METODOLOGI PENELITIAN}

Metode penelitian dimulai pada tahap perencanaan, yaitu merupakan tahap awal yang dilakukan dalam penelitian. Hal ini sangat penting karena perencanaan akan menentukan bagaimana kedepannya sebuah sistem akan di kembangkan. Setelah itu data yang akan digunakan dalam penelitian ini bersifat primer maupun sekunder dengan teknik pengumpulan data. Setelah pengumpulan data maka dilakukan analisa sistem yang berjalan dan memberikan analisa sistem usulan lalu melakukan perancangan sistem. Setelah melakukan perancangan sistem, maka dilakukan coding yaitu bagian dari pembuatan kode-kode program yang dibuat berdasarkan seluruh rancangan yang telah dibuat sebelumnya, termasuk pengolahan data, dan pembuatan peta akhir. Tahap yang terakhir yang dilakukan adalah melakukan dokumentasi dari semua tahap yang telah dilakukan dari awal sampai akhir.

\section{C.1. Perencanaan}

Tahap perencanaan dilakukan untuk mengidentifikasi permasalahan yang terjadi. Tahap ini dilakukan dengan cara wawancara dan observasi. Wawancara dilakukan kepada Dekan dan pegawai Sub Bagian Administrasi Umum Fakultas Sains dan Teknologi. Observasi dilakukan pada Bagian Administrasi Umum dan Keuangan Fakultas Sains dan Teknologi. Selain untuk mengindentifikasi masalah dan kebutuhan pengguna, wawancara dan observasi juga menghasilkan data primer dan data sekunder.

\section{C.2. Analisa dan Perancangan}

Sistem yang dibangun terdiri dari dua bagian, sistem backend berbasis web untuk administrator, Dekan, Wakil Dekan, Kasubag Administrasi Umum dan aplikasi Complaint Management System berbasis mobile untuk Mahasiswa. Pada tahap ini, baik untuk aplikasi maupun sistem backend dilakukan: (1) analisa sistem yang sedang berjalan; (2) analisa sistem usulan; dan (3) perancangan sistem. Analisa sistem yang sedang berjalan dilakukan dengan cara menganilisis ha wawancara dan observasi serta dokumen-dokumen yang didapat 
dari tahap perencanaan. Sedangkan pada tahap analisa sistem usulan dibuat Flowchart sistem usulan. Pada tahap perancangan sistem dilakukan pembuatan use case diagram, class diagram, perancangan basis data, perancangan struktur menu serta perancangan antarmuka.

\section{C.3. Implementasi dan Pengujian}

Berikut merupakan lingkungan implementasi pada penelitian ini.

1) Aplikasi berbasis mobile

(a) Perangkat keras

- Smartphone: Moto G5S plus

(b) Perangkat lunak

- Nox

- Sistem operasi: Android KitKat 4.4.2

2) Sistem backend berbasis website

(a) Perangkat keras

- Processor: Intel i5 $2.4 \mathrm{Ghz}$

- Memory: RAM $4 \mathrm{~Gb}$

(b) Perangkat lunak

- Sistem operasi: Windows 8

- Browser: Chrome

- Bahasa pemrograman: PHP

- Framework: Bootstrap

- Database: MySql

Pengujian aplikasi dilakukan dengan menggunakan metode Black Box dan User Acceptance Test (UAT). Skenario uji dilakukan pada setiap fitur-fitur semua aktor.

\section{ANALISA DAN PERANCANGAN}

\section{D.1. Analisa Sistem yang Sedang Berjalan}

Proses sistem handling complaint pada

Fakultas Sains dan Teknologi yang sedang berjalan masih menggunakan metode manual dengan prosedur sebagai berikut:

1. Mahasiswa membuat surat perihal komplain dan memasukkan surat tersebut ke Sub-bagian Administrasi Umum melalui pegawai administrasi umum.

2. Surat diterima oleh pegawai Sub-Bagian Administrasi Umum dan memberikan penomoran surat pada lembar disposisi. Setelah diberikan penomoran surat, maka surat tersebut diteruskan kepada Kepala Sub-bagian (Kasubag) Administrasi Umum.

3. Surat diterima oleh Kasubag Administrasi Umum. Kasubag Administrasi Umum menandatangani surat pada lembar disposisi bahwasannya permasalahan yang diajukan akan ditindaklanjuti. Setelah itu surat diserahkan kepada Dekan.

4. Dekan menerima surat dan mendisposisikannya kepada Wakil Dekan sesuai dengan bidang permasalahan pada surat tersebut.
5. Surat diterima oleh Wakil Dekan dan diberikan solusi dari permasalahan tersebut. Solusi dapat dituliskan pada lembar disposisi.

6. Setelah itu surat kembali ke Sub Bagian Administrasi Umum agar dapat menyelesaikan pekerjaan sesuai dengan solusi yang sudah diberikan oleh Wakil Dekan.

\section{D.2. Analisa Sistem Usulan}

Sistem baru yang akan di bangun memanfaatkan sistem berbasis Android sebagai Front End System untuk tingkatan hak akses mahasiswa dan sistem berbasis Web sebagai Back End System untuk tingkatan pihak hak akses Kasubag Administrasi Umum, Dekan, Wakil Dekan II dan Administrator. Sistem ini memiliki beberapa data masukan yaitu: data komplain yang diinputkan oleh mahasiswa, data tanggapan yang diinputkan oleh Wakil Dekan II, Data Mahasiswa, dan Data User. Kemudian data-data tersebut akan disimpan kedalam Databases.

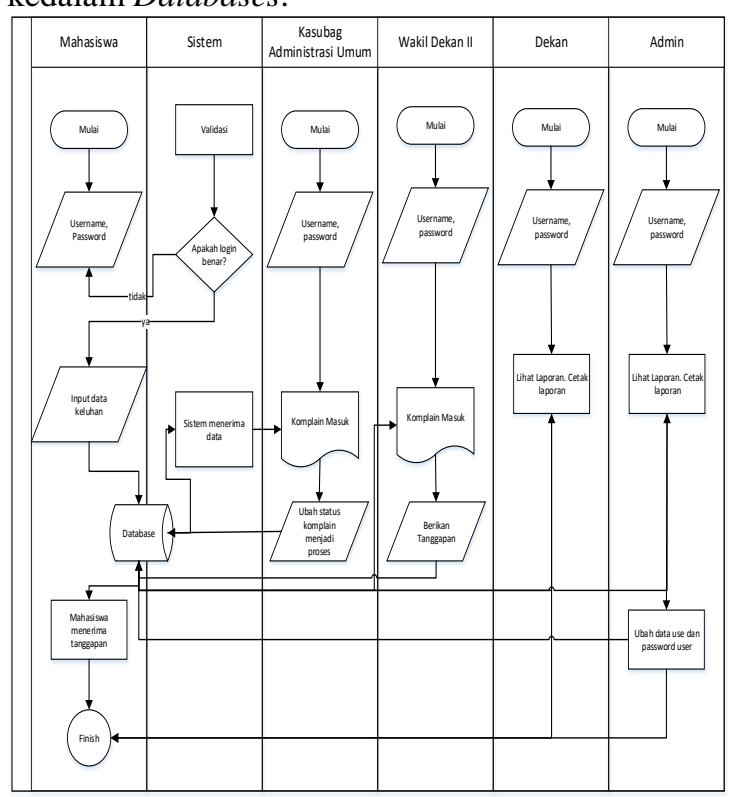

Gambar 2. Analisa Sistem Usulan

Beberapa kelebihan yang dimiliki oleh aplikasi yang dibangun adalah: (1) Mahasiswa dapat mengirimkan komplain kapanpun dan dimanapun; (2) Pihak Fakultas bisa mengelola komplain kapanpun dan dimanapun berada. Hal ini akan meminimalisir bahkan mempersingkat waktu perealisasian komplain; (3) Tidak akan terjadi penumpukan berkas-berkas pengaduan mahasiswa pada lemari berkas; (4) Resiko kehilangan dan kerusakan data pengaduan dapat teratasi karena data komplain tersimpan pada database dan dapat dicetak berkali-kali.

Untuk dapat melihat hasil analisa sistem usulan, dapat dilihat pada Gambar 2 .

\section{D.2.1. Perancangan Sistem}

Berikut Use case diagram sistem, class diagram dan struktur menu: (Gambar 3, 4 dan 5) 


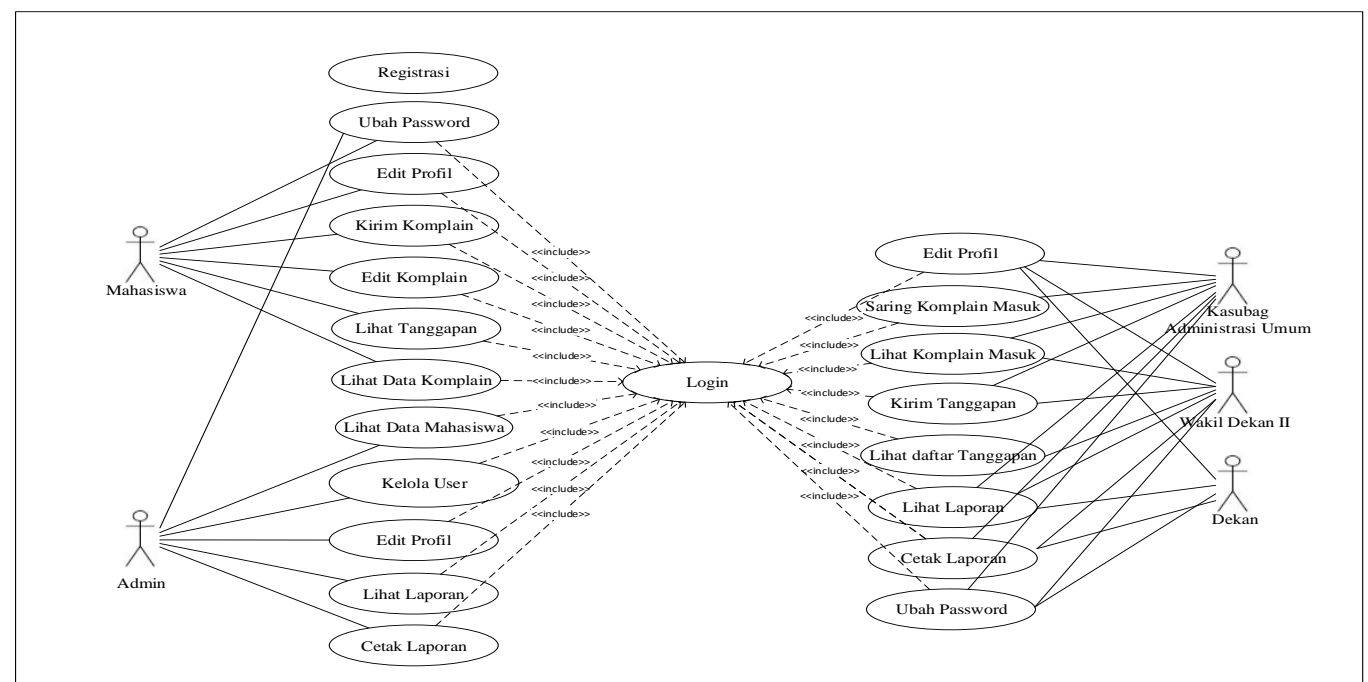

Gambar 3. Usecase Diagram

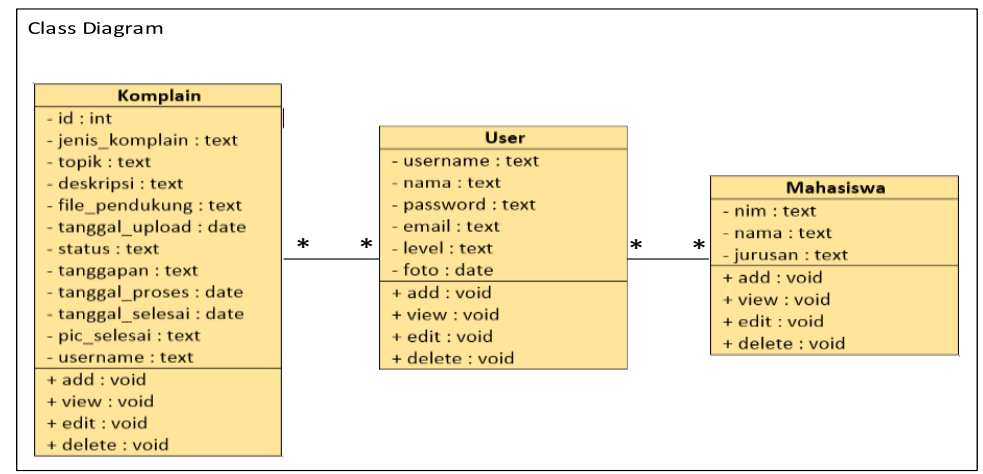

Gambar 4. Class Diagram

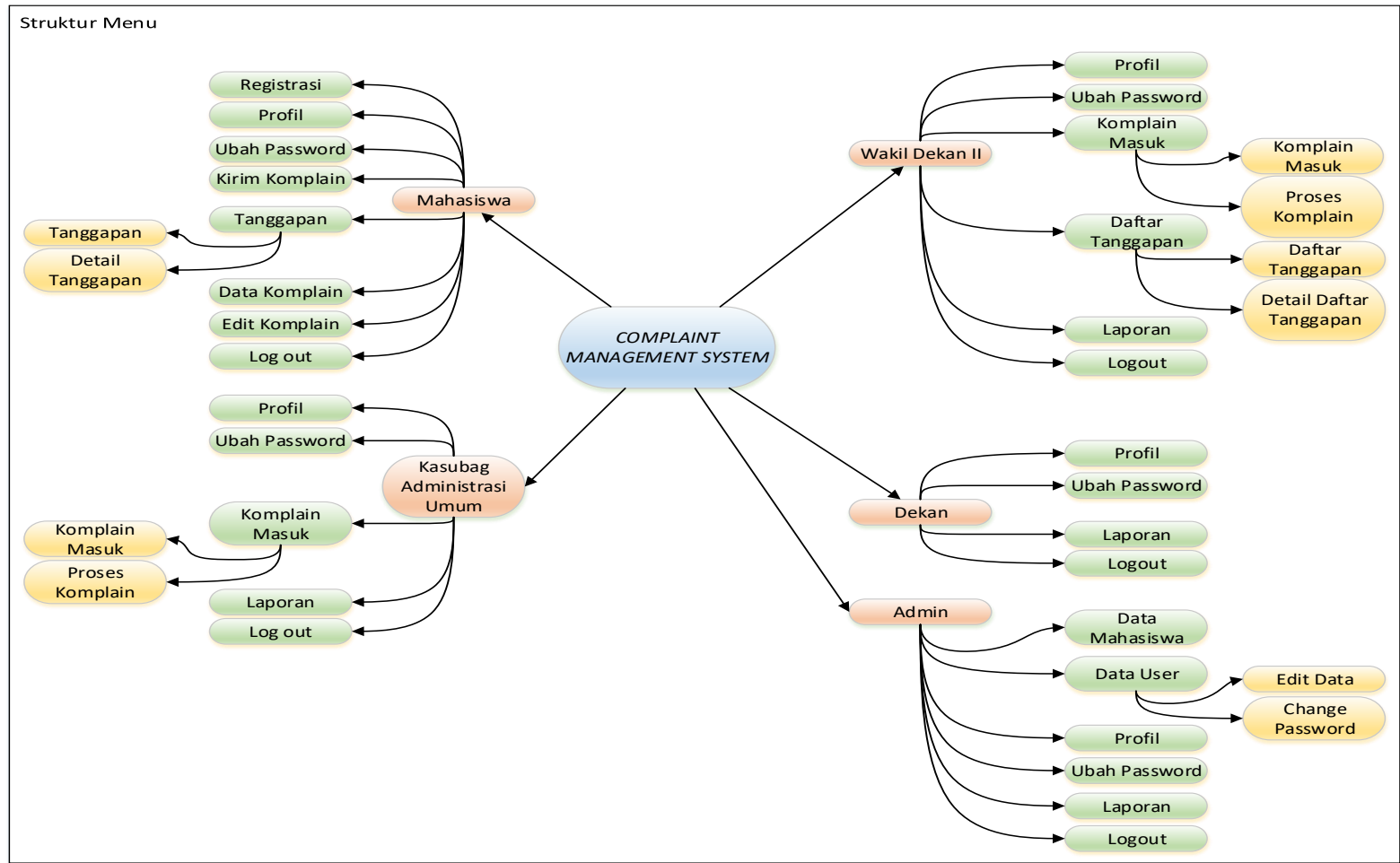

Gambar 5. Struktur Menu 
Jurnal Ilmiah Rekayasa dan Manajemen Sistem Informasi, Vol. 5, No. 1, Februari 2019, Hal. 42-47 e-ISSN 2502-8995 p-ISSN 2460-8181

\section{E. HASIL DAN PEMBAHASAN}

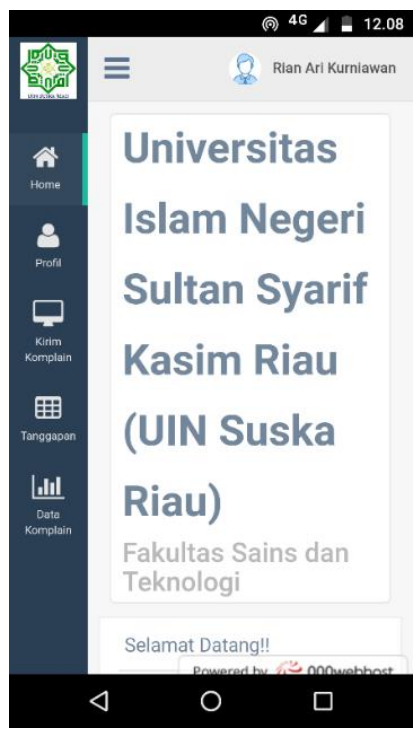

Gambar 6. Tampilan Utama Hak Akses Mahasiswa

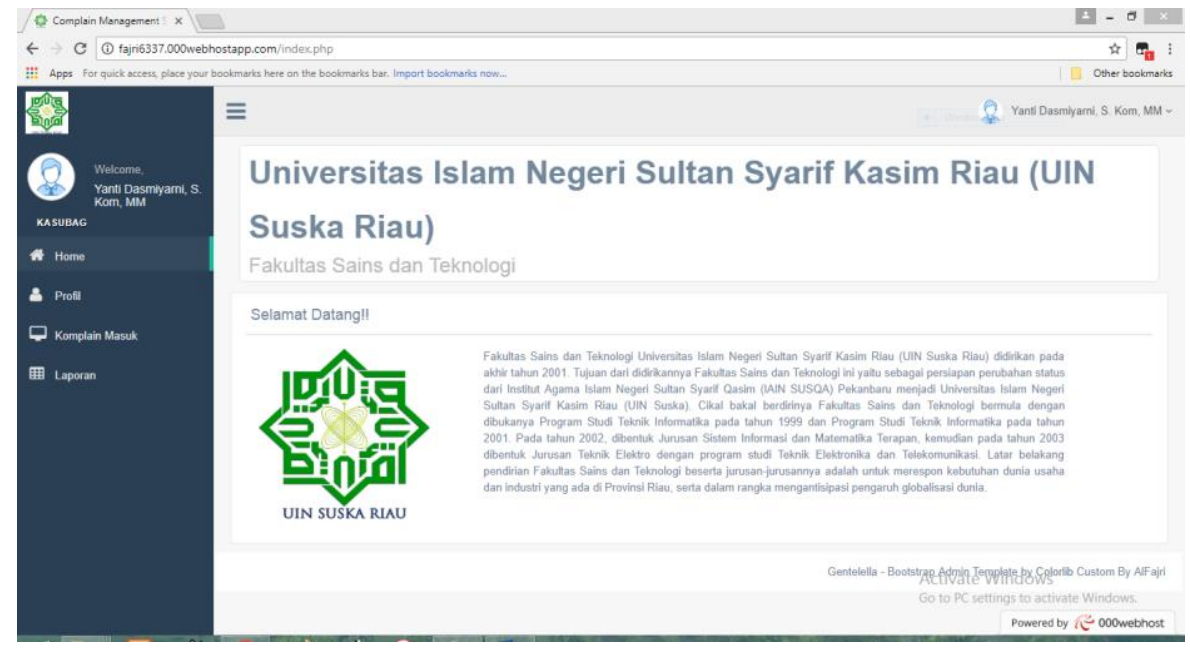

Gambar 7. Tampilan Utama Hak Akses Kasubag Administrasi Umum

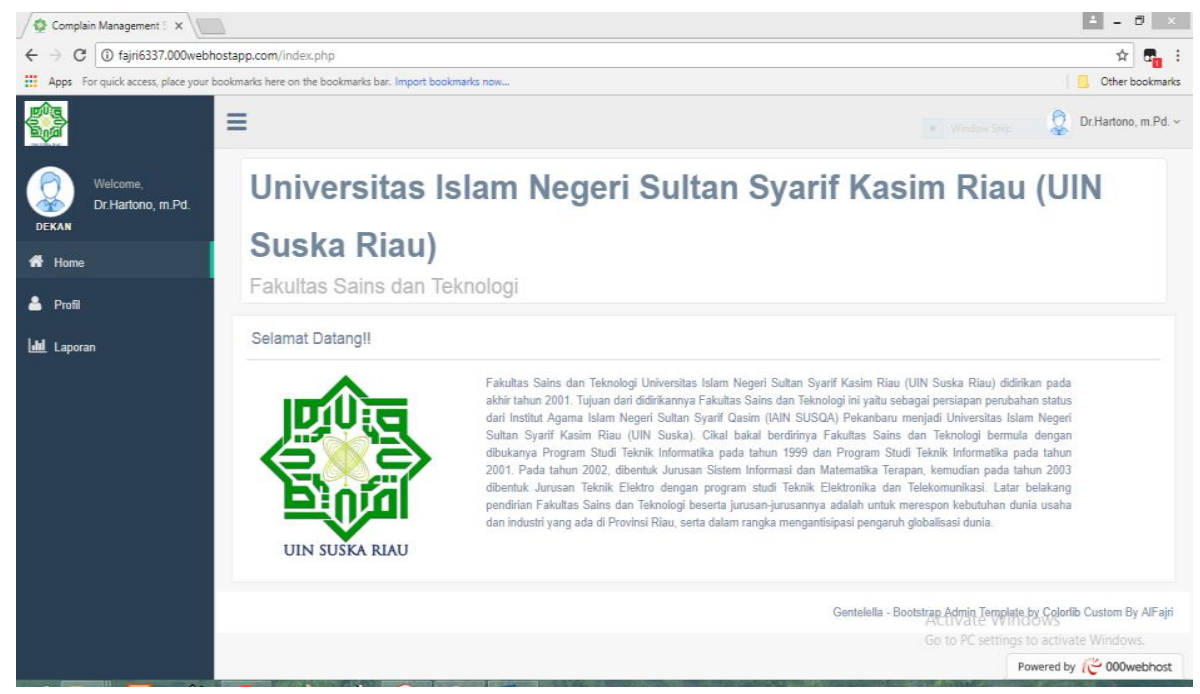

Gambar 8. Tampilan Utama Hak Akses Dekan 


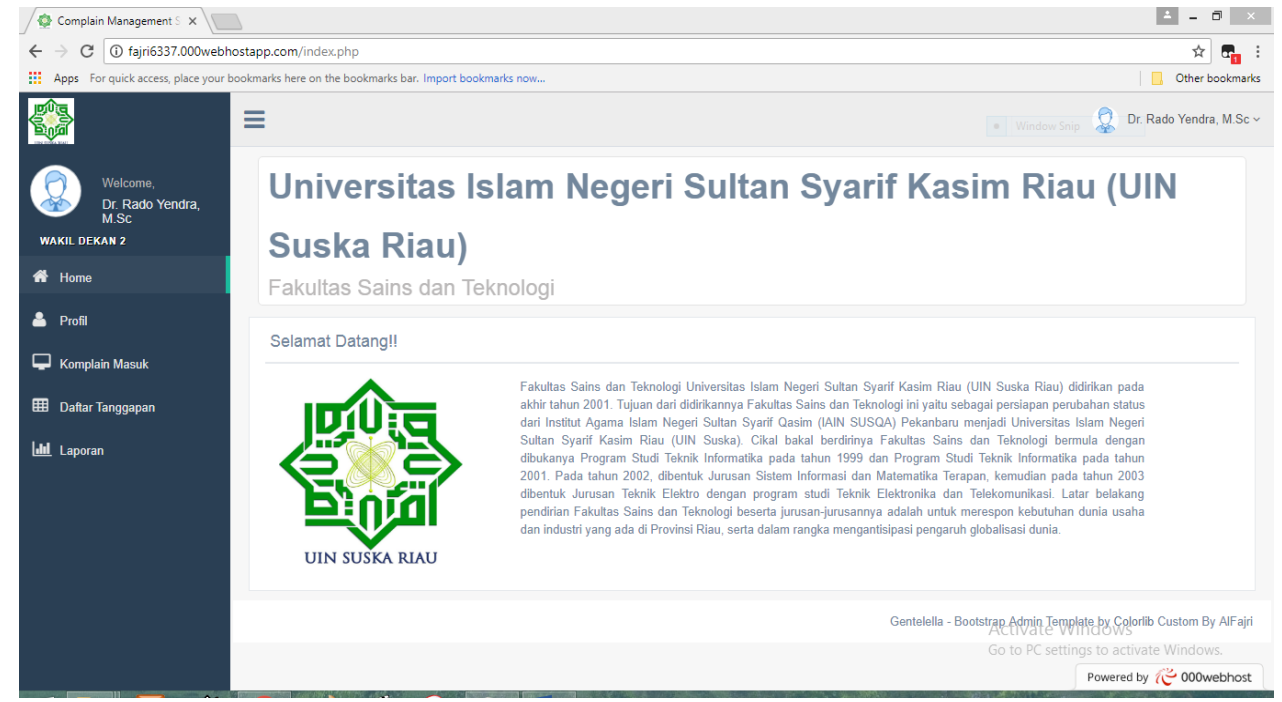

Gambar 9. Tampilan Utama Hak Akses Wakil Dekan

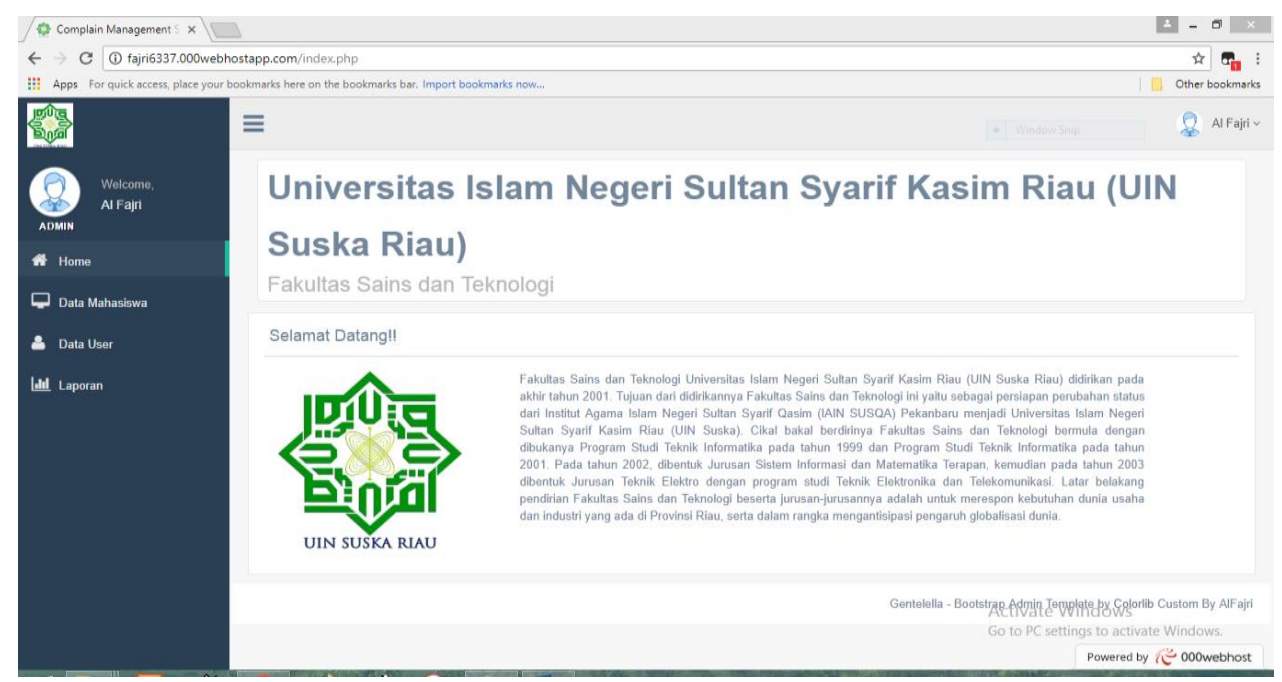

Gambar 10. Tampilan Utama Hak Akses Admin

Gambar 6, 7, 8, 9, dan 10 merupakan tampilan dari hasil dari pengembangan sistem yang telah dibangun dalam penelitian ini.

\section{F. KESIMPULAN}

Berdasarkan uraian yang telah dibahas maka terdapat kesimpulan bahwa Aplikasi Complaint Management System ini diharapkan dapat diimplementasikan oleh Fakultas Sains dan Teknologi UIN Suska Riau dan sebagaimana dilihat dari manfaatnya untuk mahasiswa salah satunya dapat mempermudah dalam hal penyampaian komplain/keluhan serta membantu Fakultas Sains dan Teknologi UIN Suska dalam perencanaan strategis dan evaluasi sasaran program manajemen dimasa yang akan datang serta menyajikan informasi yang berguna bagi pengelola dan pengambil keputusan untuk membantu memecahkan permasalahan, menentukan pilihan atau membuat kebijakan.

\section{REFERENSI}

[1] A. Faed and D. Forbes. 2010. Impact of Customer Management System in Improving Customer Retention: Optimization of Negative Customer Feedback, vol. 4, no. 12, pp. 171175 ,.

[2] Teguh Arifianto. 2011 Membuat Interface Aplikasi Android Lebih Keren dengan LWUIT. Yogyakarta: Andi,.

[3] Sholiq. 2006. Pemodelan Sistem Informasi Berorientasi Objek dengan Uml. Yogyakarta: Graha Ilmu.

[4] Nugroho. 2012. Rekayasa Perangkat Lunak Berorientasi. Yogyakarta: Andi. 
Jurnal Ilmiah Rekayasa dan Manajemen Sistem Informasi, Vol. 5, No. 1, Februari 2019, Hal. $42-47$ e-ISSN 2502-8995 p-ISSN 2460-8181 